\title{
The Autonomic Reflex Screen in Healthy Participants from Southwestern Ontario
}

\author{
Colleen T. Ives, Michael J. Berger, Kurt Kimpinski
}

\begin{abstract}
Background: The autonomic reflex screen (ARS) is a composite of well-defined tests of various autonomic domains and is an essential part of the diagnosis of autonomic disorders. Institutional and regional differences exist and necessitate the ongoing development of control values for the ARS. Here we present data obtained from healthy participants from Southwestern Ontario. Methods: A total of 121 healthy individuals underwent quantitative sudomotor axon reflex testing (QSART), heart rate response to deep breathing $\left(\mathrm{HR}_{\mathrm{DB}}\right)$, and Valsalva maneuver using standard protocols as part of the ARS. Results: Sweat volumes obtained during QSART are presented by site (forearm, proximal leg, distal leg and foot) and by gender. Data is expressed as the mean sweat volume per site with the associated 2.5th, 5th and 95th percentiles. Data for males and females is also stratified by age group (14-25, 26-40 and 41-76 years). Measurements of cardiovagal parasympathetic function including $\mathrm{HR}_{\mathrm{DB}}$ and Valsalva ratio are stratified by age group (14-25, 2640 and 41-76 years). Data is expressed as the mean with associated percentiles (2.5, 5, 95 and 97.5 percentiles). Conclusions: The current manuscript provides control data for the various components of the ARS to aid in the diagnosis of autonomic disorders.
\end{abstract}

RÉSUMÉ: La grille de dépistage des réflexes autonomes chez des sujets en bonne santé du sud-ouest de l'Ontario. Contexte : La grille de dépistage des réflexes autonomes (GDRA) est composée de tests bien définis portant sur des fonctions autonomes variées et elle est une partie essentielle du diagnostic des maladies du système nerveux autonome. Il existe des différences institutionnelles et régionales, de là la nécessité d'établir des valeurstémoins pour la GDRA. Nous présentons les données obtenues chez des sujets sains du sud-ouest de l'Ontario. Méthode : Un protocole standard de test quantitatif de l'axone réflexe sudomoteur (QARS), de la réponse du rythme cardiaque à la respiration profonde (RCRP) et de la manœuvre de Valsalva a été utilisé chez 121 individus en bonne santé dans le cadre de la GDRA. Résultats : Les volumes de sueur obtenus pendant le QARS sont présentés par région (avant-bras, région proximale de la jambe, région distale de la jambe et pied) et par sexe. Les données rapportées sont le volume de sueur moyen par région ainsi que les $2,5 \mathrm{e}, 5 \mathrm{e}$ et $95 \mathrm{e}$ percentiles. Les données pour les hommes et pour les femmes sont également stratifiées par groupe d'âge (14 à 25 ans, 26 à 40 ans et 41 à 76 ans). Les mesures de la fonction parasympathique cardiaque incluant la RCRP et le rapport de Valsalva sont également rapportés pour les mêmes groupes d'âge ainsi que la moyenne pour les percentiles 2,5e, 5e, 95e et 97,5e percentiles. Conclusions : Cet article présente des données témoins pour les différentes composantes de la GDRA en vue de faciliter le diagnostic des maladies du système nerveux autonome.

Can J Neurol Sci. 2013; 40: 848-853

The autonomic reflex screen (ARS) is a composite of welldefined tests of various autonomic domains and includes quantitative sudomotor axon reflex testing (QSART), heart rate response to deep breathing $\left(\mathrm{HR}_{\mathrm{DB}}\right)$, and Valsalva maneuver ${ }^{1-3}$. The components of the ARS have been well validated and control values have been previously published ${ }^{4}$. The ARS is a valuable tool in the evaluation and diagnosis of specific entities of autonomic dysfunction such as neurogenic orthostatic hypotension, Postural Tachycardia Syndrome and specific disorders associated with autonomic impairment such as diabetic autonomic neuropathy, amyloidosis and Multiple Systems Atrophy ${ }^{5-9}$. Furthermore, the ARS provides a standardized measure that correlates well with autonomic dysfunction in general ${ }^{10}$.

However, differences in autonomic function between geographic regions can occur, and control values for a given laboratory and region are important for accurate laboratory diagnosis $^{3}$. Furthermore, the standardized data currently available are based on measurements obtained from a single laboratory and sample population and subtle differences in methodology and technique can exist between laboratories. These factors necessitate a reevaluation of control values for the ARS for different regions.
The present QSART data were obtained using a gel-based vehicle for delivery of acetylcholine chloride (ACh) solely using the Q-Sweat apparatus (WR Medical Electronics Co., Stillwater, $\mathrm{MN})$, which is the commercially available version of the Mayobuilt sudorometer ${ }^{3,11}$. Previous studies have most commonly reported QSART data obtained from the Mayo-built sudorometer using a solution-based vehicle for delivery of ACh $(10 \% \text { weight/volume }(\mathrm{w} / \mathrm{v}) \text { ionic solution })^{9,12,13}$, with a normative database having been established using this methodology ${ }^{4}$. Data for QSART from the Mayo-built sudorometer using a gel-based vehicle for delivery ${ }^{14,15}$, as well as QSART data using Q-Sweat in conjunction with a solutionbased vehicle for delivery of $\mathrm{ACh}^{11,16}$, including a normative

From the Department of Clinical Neurological Sciences (CTI, KK), University Hospital, London Health Sciences Centre; Schulich School of Medicine \& Dentistry (MJB, KK), Western University, London, Ontario, Canada.

Received April 3, 2013. Final Revisions Submitted June 7, 2013.

Correspondence to: Kurt Kimpinski, Rm. C7-131, University Hospital, London Health Sciences Centre, 339 Windermere Road, London, Ontario, N6A 5A5, Canada. Email: kkimpin@uwo.ca. 
database in Chinese participants ${ }^{17}$, have also been reported. However, a normative database for Q-Sweat using a gel-based vehicle for delivery of ACh has not yet been established.

Such a database is of great importance, given that Q-Sweat is the standard equipment commercially available relevant to the majority of practice in Canada ${ }^{11}$. The Q-Sweat data presented relied on a gel-based vehicle for delivery of $\mathrm{ACh}$, which provides a more efficient test and may improve patient safety ${ }^{14,15}$.

The objective of the current study was to provide control values from 121 healthy individuals with respect to sweat volumes obtained at standard sites (forearm, proximal leg, distal leg and foot) using the Q-Sweat apparatus in performing QSART testing with a gel electrode method. Furthermore, we provide data on the assessment of cardiovagal parasympathetic function including HRDB and Valsalva ratio (VR). Data from the head-up tilt component of the ARS will be presented as part of a separate publication which addresses the complexities of establishing normative values for this test.

\section{Methods}

\section{Subjects}

Subject characteristics are presented in Table 1. Subjects included in this study ranged in age from 14-76 years. Subjects were reviewed to ensure they did not have a history of orthostatic and/or autonomic dysfunction. Preliminary evaluations were performed by a neurologist (KK) and included a neurological exam and nerve conduction studies in the lower extremity to help exclude neuropathy. Further exclusion criteria included one or more of the following: i) pregnant or lactating females, ii) the presence of any cause of autonomic failure, iii) the presence of failure of other organ systems or systemic illness that can affect autonomic function or the subject's ability to cooperate. These included dementia, pheochromocytoma, heart failure, hypertension, renal or hepatic disease, severe anemia, alcoholism, malignant neoplasms, hypothyroidism, sympathectomy, or cerebrovascular accidents, iv) concomitant therapy with anticholinergic, alpha- and beta-adrenergic antagonists, or other medication which could interfere with testing of autonomic function, v) clinically significant coronary artery disease. A total of 121 subjects met the above criteria and were included in the study. Ethical approval for the study was obtained from the local institutional ethics review board and written consent was obtained from each participant prior to study commencement.

\section{Quantitative sudomotor axon reflex testing}

Studies were completed in the Autonomic Disorders Laboratory at Western University, London, Ontario using the QSweat device (WR Medical Electronics Co., Stillwater, MN) and multi-compartmental sweat capsules ${ }^{4}$ to perform QSART at four standard sites (forearm, proximal leg, distal leg and foot). In order to assess the integrity of the postganglionic sympathetic sudomotor axon, QSART was performed as previously described $^{12}$. Control of room temperature and humidity were maintained $\left(23^{\circ} \mathrm{C}\right.$ and $25-35 \%$, respectively). Skin preparations were performed according to standard clinical protocol which involves a four-step cleaning process (acetone, alcohol, water and dry gauze $)^{3}$. A baseline sweat response was recorded. Once baseline was established, iontophoresis was performed with a stimulus of $2 \mathrm{~mA}$ constant current applied for five minutes to the stimulus compartment. The iontophoresis was performed using a gel preparation of $0.55 \mathrm{M}$ ACh in a $2.4 \% \mathrm{wt} . / \mathrm{v}$ agarose gel. Sweat responses were recorded for an additional five minutes after discontinuation of the stimulus.

\section{Heart rate response to deep breathing}

We performed HRDB by measuring heart rates in a supine position using an electrocardiography (ECG) device (Model 3000 Cardiac Trigger Monitor, IVY Biomedical Systems, Inc., Branford, CT). Baseline recordings were obtained for one minute. Subjects were then asked to perform eight deep breathing cycles using visual cueing at a rate of six cycles per minute. The five highest consecutive differences in peak to trough heart rates were automatically selected by the WR TestWorks $^{\text {TM }}$ software and manually adjusted if necessary. The values obtained were averaged to produce an average heart rate difference ${ }^{1,2}$.

\section{Valsalva ratio}

The VR was evaluated by measuring heart rate response to the Valsalva maneuver produced by forced exhalation into a standard Valsalva maneuver tube (WR Medical Electronics Co., Stillwater, MN) for 15 seconds at a pressure of $40 \mathrm{mmHg}$. Beatto-beat blood pressures and heart rates were measured using the Nexfin hemodynamic monitoring system (BMEYE Cardiovascular, Amsterdam, Netherlands). If necessary, the accuracy of beat-to-beat blood pressure was verified prior to beginning the Valsalva maneuver by using a sphygmomanometer cuff and a mercury manometer over the brachial artery. The VR was calculated by comparing the maximal heart rate during Valsalva maneuver to the minimum heart rate within 30 seconds of release of Valsalva maneuver ${ }^{1,2}$.

\section{Data and statistical analysis}

Descriptive statistics are presented as mean \pm standard deviation and percentiles (2.5th, 5th, 95th and 97.5th) where indicated. For each test, we evaluated associations with age and gender using a stepwise multiple regression analysis with an alpha level of 0.05 used to denote significance. The results of these analyses, in addition to normative percentiles, were presented graphically for select tests according to the methods outlined by O'Brien and Dyck $(1995)^{18}$. All statistical analyses were performed using SPSS $®$ statistical software version 19 for Windows (SPSS, Inc., Chicago, IL).

\section{RESULTS}

A total of 121 healthy subjects were included in the current study and their characteristics are presented in Table 1.

For QSART testing, the effect of gender was significant at all four sites, and age was also significant at the distal leg and foot sites. The regression equations for each site are as follows: forearm, $Y=1.932-0.974 X$; proximal leg, $Y=1.993-0.781 X$; where $Y$ is total sweat volume $(\mu \mathrm{L})$ and $X$ is gender $(0$, male; 1 , female). For distal leg, $Y=2.890-1.133 X_{1}-0.016 X_{2}$; and for foot, $Y=1.907-0.550 X_{1}-0.010 X_{2}$, where $Y$ is total sweat volume $(\mu \mathrm{L}), X_{1}$ is gender ( 0 , male; 1 , female), and $X_{2}$ is age in 
Table 1: Subject characteristics

\begin{tabular}{lc}
\hline Variable & $\boldsymbol{n}=\mathbf{1 2 1}$ \\
\hline Age $($ years $)$ & $35 \pm 16(14-76)$ Median: 27 \\
Sex & $58 \mathrm{~m}, 63 \mathrm{f}$ \\
Height $(\mathrm{cm})$ & $171 \pm 9(150-192)$ \\
Weight $(\mathrm{kg})$ & $72.5 \pm 15.0(45.4-145.5)$ \\
Age group: & \\
14-25 years & $\mathrm{n}=49(21 \mathrm{~m}, 28 \mathrm{f})$ \\
26-40 years & $\mathrm{n}=42(21 \mathrm{~m}, 21 \mathrm{f})$ \\
41-76 years & $\mathrm{n}=30(16 \mathrm{~m}, 14 \mathrm{f})$ \\
\hline
\end{tabular}

Values expressed as mean $\pm \mathrm{SD}$. Data in parentheses indicate range. $\mathrm{m}$, male; f, female.

years. Total sweat volumes obtained during QSART stratified by gender are presented for each site (Table 2). Data for males (Table 3) and females (Table 4) is also stratified by age group (14-25, 26-40 and 41-76 years). Data is expressed as the average sweat volume per site with the associated 2.5 th, 5th and 95th percentiles also presented. It should be noted that very low sweat volumes calculated for 2.5 th and 5 th percentiles (e.g. $0.02 \mu \mathrm{L}$ $0.04 \mu \mathrm{L})$ at select sites may have been erroneously low as a result of technical issues. Figure 1 depicts scatter plots including percentiles of QSART total sweat volumes at the foot site as a function of age for male (Figure 1a) and female (Figure 1b) subjects.

Our results demonstrated that $H_{\mathrm{DB}}$ and $\mathrm{VR}$ varied significantly by age. As these measures were not found to vary significantly by gender, the results for males and females were combined. The relationship for $\mathrm{HR}_{\mathrm{DB}}$ is expressed by the regression equation, $Y=31.66-0.306 X$, where $Y$ is average heart rate difference (bpm), and $X$ is age in years (Figure 2a). The relationship for VR is expressed by the regression equation, $Y=2.269-0.010 X$, where $Y$ is Valsalva ratio, and $X$ is age in years (Figure 2b). Measurements of cardiovagal parasympathetic function including $\mathrm{HR}_{\mathrm{DB}}$ and $\mathrm{VR}$ are shown in Tables 5 and 6, respectively. Data for $\mathrm{HR}_{\mathrm{DB}}$ and VR is stratified by age group (14-25, 26-40 and 41-76 years) and data is expressed as the mean and by percentile (2.5th, 5th, 95th and 97.5th percentiles).

\section{DISCUSSION}

\section{ARS normative data and comparison to prior studies}

The results of the present study compare favorably with the findings from a previous study of healthy control subjects by Low et al $(1997)^{4}$. In line with the QSART results from 357 subjects acquired using the Mayo-built sudorometer and an ACh solution $^{4}$, a significant effect of gender was found for all four testing sites, with greater sweat volumes for males than for females (Table 2). These results are in keeping with several previous studies that have demonstrated higher sweat volumes in males $^{12,13}$. Sweat volumes were approximately twice as great for males as for females at the forearm and distal leg sites.

In addition to gender, age was found to have a significant effect on QSART results at the distal leg and foot sites. As a result of the differences in sweat volume between genders, further stratification based on age was performed separately for male and female data (Tables 3, 4, Figure 1). However, we were generally unable to show a distinction between the lower percentiles (2.5th and 5th percentiles) when sweat volumes were separated by age and gender due to small sample size. The QSART results demonstrated a pattern of lower mean sweat

Table 2: QSART responses (total sweat volume $[\mu \mathrm{L}])$ : Mean, 2.5th, 5th, and 95th percentile values

\begin{tabular}{|c|c|c|c|c|c|c|c|c|}
\hline \multirow[b]{2}{*}{ Sites } & \multicolumn{4}{|c|}{ Male } & \multicolumn{4}{|c|}{ Female } \\
\hline & Mean & $2.5^{\text {th }}$ & $5^{\text {th }}$ & $95^{\text {th }}$ & Mean & $2.5^{\text {th }}$ & $5^{\text {th }}$ & $95^{\text {th }}$ \\
\hline Forearm & 1.93 & 0.12 & 0.27 & 5.16 & 0.96 & 0.07 & 0.11 & 2.61 \\
\hline Proximal leg & 1.99 & 0.16 & 0.46 & 4.98 & 1.21 & 0.20 & 0.32 & 3.28 \\
\hline Distal leg & 2.32 & 0.08 & 0.43 & 4.41 & 1.22 & 0.07 & 0.17 & 2.39 \\
\hline Foot & 1.54 & 0.10 & 0.33 & 3.23 & 1.01 & 0.24 & 0.27 & 2.54 \\
\hline
\end{tabular}

QSART, quantitative sudomotor axon reflex test.

Table 3: Male QSART responses (total sweat volume $[\mu \mathrm{L}]$ ): Mean, 2.5th, and 5th percentile values

\begin{tabular}{|c|c|c|c|c|c|c|c|c|c|}
\hline \multirow[b]{2}{*}{ Sites } & \multicolumn{3}{|c|}{ 14-25 Years } & \multicolumn{3}{|c|}{ 26-40 Years } & \multicolumn{3}{|c|}{ 41-76 Years } \\
\hline & Mean & $2.5^{\text {th }}$ & $5^{\text {th }}$ & Mean & $2.5^{\text {th }}$ & $5^{\text {th }}$ & Mean & $2.5^{\text {th }}$ & $5^{\text {th }}$ \\
\hline Forearm & 2.06 & 0.31 & 0.31 & 2.05 & 0.08 & 0.08 & 1.64 & 0.21 & 0.21 \\
\hline Proximal leg & 2.24 & 0.48 & 0.48 & 1.84 & 0.38 & 0.39 & 1.92 & 0.03 & 0.03 \\
\hline Distal leg & 2.54 & 0.60 & 0.60 & 2.34 & 0.19 & 0.22 & 1.98 & 0.02 & 0.02 \\
\hline Foot & 1.99 & 0.44 & 0.44 & 1.15 & 0.25 & 0.25 & 1.52 & 0.03 & 0.03 \\
\hline
\end{tabular}

QSART, quantitative sudomotor axon reflex test. 




Figure 1: QSART total sweat volumes at foot site as a function of age in male (A) and female (B) subjects. Lines depict 2.5 th and 5 th percentiles. To prevent overlap, 5th percentile lines moved upward by $0.08 \mu \mathrm{L}$ increment.

volumes with age in male and female subjects at the distal leg and foot sites. These results are similar to those from Low et al $(1997)^{4}$, which demonstrated significant effects of age at the distal leg and foot sites (also finding a significant effect at the proximal leg site) with respect to declining mean sweat volumes. Examining the significant influence of age on $\mathrm{HR}_{\mathrm{DB}}$ for data pooled across genders, mean values of average heart rate difference beats per (bpm) were found to progressively decline with age (Table 5, Figure 2A). This finding of a reduction in heart rate variation with age is again in line with previous study results in 376 subjects $^{4}$, and has been similarly demonstrated in a myriad of previous studies involving healthy control subjects $^{13,19-21}$. There was a lack of differentiation between the 2.5 th and 5 th percentiles in the higher age ranges with respect to heart rate variability due to limited control subjects in these age ranges (Table 5, Figure 2A). It is difficult to recruit subjects in these age ranges due to the increased prevalence of confounding health factors such as arrhythmia and cardiac/blood pressure medications that can affect heart rate variability. A significant effect of age was also found for VR results in the present study (Table 6, Figure 2B). In contrast, Low et al (1997) ${ }^{4}$ demonstrated a significant effect for both age and gender on the VR.

\section{Sweat onset latencies not reliable or clinically helpful versus volumes}

We chose to report total sweat volume, but not response latency for the QSART portion of this study. Measured as the time to sweating onset following application of the stimulus, the



Figure 2: Average heart rate difference as a function of age $(H R D B)(A)$ and Valsalva ratio as a function of age (B). Lines depict 2.5th and 5thpercentiles as well as overall stepwise regression line. To prevent overlap, 5th percentile line for Valsalva ratio plot moved upward by increment of 0.08. Bpm, beats per minute; HR, heart rate. 
Table 4: Female QSART responses (total sweat volume $[\mu \mathrm{L}])$ : Mean, 2.5 th, and 5th percentile values

\begin{tabular}{|c|c|c|c|c|c|c|c|c|c|}
\hline \multirow[b]{2}{*}{ Sites } & \multicolumn{3}{|c|}{ 14-25 Years } & \multicolumn{3}{|c|}{ 26-40 Years } & \multicolumn{3}{|c|}{ 41-76 Years } \\
\hline & Mean & $2.5^{\text {th }}$ & $5^{\text {th }}$ & Mean & $2.5^{\text {th }}$ & $5^{\text {th }}$ & Mean & $2.5^{\text {th }}$ & $5^{\text {th }}$ \\
\hline Forearm & 0.98 & 0.19 & 0.20 & 1.02 & 0.03 & 0.04 & 0.81 & 0.13 & 0.13 \\
\hline Proximal leg & 1.24 & 0.36 & 0.36 & 1.42 & 0.52 & 0.52 & 0.89 & 0.17 & 0.17 \\
\hline Distal leg & 1.53 & 0.08 & 0.12 & 1.12 & 0.24 & 0.24 & 0.80 & 0.06 & 0.06 \\
\hline Foot & 1.20 & 0.27 & 0.28 & 1.02 & 0.22 & 0.22 & 0.66 & 0.36 & 0.36 \\
\hline
\end{tabular}

Values expressed as mean $\pm \mathrm{SD}$. Data in parentheses indicate range. $\mathrm{m}$, male; f, female.

Table 5: $\mathrm{HR}_{\mathrm{DB}}$ (average heart rate difference $\left.[\mathrm{bpm}]\right): \mathbf{2 . 5}, \mathbf{5}$, 95, and 97.5 percentile values

\begin{tabular}{lccc}
\hline Parameter & $\mathbf{1 4 - 2 5}$ Years & $\begin{array}{c}\mathbf{2 6 - 4 0} \\
\text { Years }\end{array}$ & $\begin{array}{c}\mathbf{4 1 - 7 6} \\
\text { Years }\end{array}$ \\
\hline Mean & 26 & 21 & 13 \\
$2.5 ; 5.0$ & $6 ; 10$ & $9 ; 11$ & $5 ; 5$ \\
$95 ; 97.5$ & $49 ; 61$ & $38 ; 43$ & $36 ;--$ \\
\hline
\end{tabular}

bpm, beats per minute; $\mathrm{HR}_{\mathrm{DB}}$, heart rate response to deep breathing

latter is not typically employed as an indicator of sudomotor function, and may be influenced by levels of skin resistance ${ }^{3}$. Furthermore, latencies can vary significantly in the context of normal sweat volumes that show reasonable test-retest reliability obtained from control subjects, further indicating that latency is not a good measure of post ganglionic sudomotor axon integrity $^{22}$.

\section{Sole use of gel electrode for QSART using only the Q-Sweat apparatus}

This has been the first study to report sudomotor data and establish a normative database for QSART using a gel-based vehicle for delivery of ACh in conjunction with the Q-Sweat apparatus. Establishment of this normative database for Q-Sweat is necessary, given that the system is the standard commercially available equipment for clinical and research evaluation of sudomotor function ${ }^{11}$.

The use of a gel-based vehicle for delivery of ACh has been shown to yield comparable sudomotor results to solution-based testing with no significant differences in patient comfort (based on Mayo-built sudorometer testing $)^{14,15}$, and offers a number of advantages. Gel formulations avoid the common technical issue of leaking associated with the use of a solution ${ }^{3,14}$, which may also improve patient safety ${ }^{15}$. Furthermore, the use of a gel better ensures surface area contact with the underlying skin ${ }^{3,14,15}$.

\section{Conclusions}

The current study provides normative data for use in the interpretation of the ARS to aid in the evaluation of dysautonomias. Our data focuses on commercially available equipment used in the ARS evaluation, increasing the clinical
Table 6: Valsalva ratio: $2.5,5,95$, and 97.5 percentile values

\begin{tabular}{lccc}
\hline Parameter & $\begin{array}{c}\mathbf{1 4 - 2 5} \\
\text { Years }\end{array}$ & $\begin{array}{c}\mathbf{2 6 - 4 0} \\
\text { Years }\end{array}$ & $\begin{array}{c}\mathbf{4 1 - 7 6} \\
\text { Years }\end{array}$ \\
\hline Mean & 2.09 & 1.93 & 1.69 \\
$2.5 ; 5.0$ & $1.63 ; 1.65$ & $1.44 ; 1.45$ & $1.25 ; 1.27$ \\
$95 ; 97.5$ & $2.73 ; 3.06$ & $2.80 ; 2.83$ & $2.37 ;--$ \\
\hline
\end{tabular}

application of these data. Furthermore, our study addresses questions regarding regional variation in autonomic parameters in that our results are in keeping with already published data and relevant to the assessment of patients in Southwestern Ontario and potentially the rest of Canada. We will continue to recruit control subjects to further increase our sample size in order to better address outstanding issues with respect to normative data for the ARS with a focus on lower ( $<18$ years) and higher $(>65$ years) age ranges and the ARS components where a significant effect for both age and gender necessitate greater sample sizes (i.e. distal leg/foot sweat volumes).

\section{ACKNOWLEDGEMENT}

This work was supported by unrestricted grant funds from the Department of Clinical Neurological Sciences Internal Research Fund.

\section{REFERENCES}

1. Low PA. Testing the autonomic nervous system. Semin Neurol. 2003;23(4):407-21.

2. Low PA, Opfer-Gehrking TL. The autonomic laboratory. Neurodiagn J. 1999;39(2):65-76.

3. Low PA, Sletten DM. Laboratory evaluation of autonomic failure. In: Low PA, Benarroch EE, editors. Clinical Autonomic Disorders. 3rd ed. Philadelphia, PA: Lippincott Williams \& Wilkins; 2008. p. 130-63.

4. Low PA, Denq JC, Opfer-Gehrking TL, Dyck PJ, O'Brien PC, Slezak JM. Effect of age and gender on sudomotor and cardiovagal function and blood pressure response to tilt in normal subjects. Muscle Nerve. 1997;20(12):1561-8.

5. Dong HK, Zeldenrust SR, Low PA, Dyck PJ. Quantitative sensation and autonomic test abnormalities in transthyretin amyloidosis polyneuropathy. Muscle Nerve. 2009;40(3):363-70. 
6. Kimpinski K, Figueroa JJ, Singer W, et al. A prospective, 1-year follow-up study of postural tachycardia syndrome. Mayo Clin Proc. 2012;87(8):746-52.

7. Kimpinski K, Iodice V, Burton DD, et al. The role of autonomic testing in the differentiation of parkinson's disease from multiple system atrophy. J Neurol Sci. 2012;317(1-2):92-6.

8. Low PA, Singer W. Management of neurogenic orthostatic hypotension: An update. Lancet Neurol. 2008;7(5):451-8.

9. Low VA, Sandroni P, Fealey RD, Low PA. Detection of small-fiber neuropathy by sudomotor testing. Muscle Nerve. 2006;34(1): 57-61.

10. Low PA. Composite autonomic scoring scale for laboratory quantification of generalized autonomic failure. Mayo Clin Proc. 1993;68(8):748-52.

11. Sletten DM, Weigand SD, Low PA. Relationship of Q-sweat to quantitative sudomotor axon reflex test (QSART) volumes. Muscle Nerve. 2010;41(2):240-6.

12. Low PA, Caskey PE, Tuck RR, Fealey RD, Dyck PJ. Quantitative sudomotor axon reflex test in normal and neuropathic subjects. Ann Neurol. 1983;14(5):573-80.

13. Low PA, Opfer-Gehrking TL, Proper CJ, Zimmerman I. The effect of aging on cardiac autonomic and postganglionic sudomotor function. Muscle Nerve. 1990;13(2):152-7.

14. Sletten DM, Kimpinski K, Weigand SD, Low PA. A novel gel based vehicle for the delivery of acetylcholine in quantitative sudomotor axon reflex testing. Auton Neurosci. 2009;150(12):127-30.
15. Sletten DM, Kimpinski K, Weigand SD, Low PA. Comparison of a gel versus solution-based vehicle for the delivery of acetylcholine in QSART. Auton Neurosci. 2010;158(1-2):123-6.

16. Abou-Zeid E, Artibee K, Shi Y, Wang L, Peltier A. Reliability of the quantitative sudomotor axon reflex test (QSART) using QSWEAT. Neurology. 2011;76(Suppl 4).

17. Chen SF, Chang YT, Lu CH, et al. Sweat output measurement of the post-ganglion sudomotor response by Q-sweat test: A normative database of chinese individuals. BMC Neurosci. 2012 Jun 8; 13:62.

18. Dyck PJ, O'Brien PC. Procedures for setting normal values. Neurology. 1995;45(1):17-23.

19. Braune S, Auer A, Schulte-Mönting J, Schwerbrock S, Lücking $\mathrm{CH}$. Cardiovascular parameters: Sensitivity to detect autonomic dysfunction and influence of age and sex in normal subjects. Clin Auton Res. 1996;6(1):3-15.

20. Wieling W, van Brederode JFM, de Rijk LG, Borst C, Dunning AJ. Reflex control of heart rate in normal subjects in relation to age: A data base for cardiac vagal neuropathy. Diabetologia. 1982; 22(3):163-6.

21. Ziegler D, Laux G, Dannehl K, et al. Assessment of cardiovascular autonomic function: Age-related normal ranges and reproducibility of spectral analysis, vector analysis, and standard tests of heart rate variation and blood pressure responses. Diabet Med. 1992;9(2):166-75.

22. Berger MJ, Kimpinski K. Test-retest reliability and minimal detectable change for quantitative sudomotor axon reflex testing. J Clin Neurophysiol. 2013 Jun;30(3):308-12. 